\title{
Criteria for Assessing the Quality of Cultivable Land in Land Use Optimization
}

\author{
Dmitry A. Danilov \\ Federal State Budget Institution \\ Leningrad research institute for \\ agricultural science «BELOGORKA» \\ Leningrad region, Gatchina district, \\ v. Belogorka, Russian Federation \\ e-mail: stown200@mail.ru
}

\author{
Alexander L. Ilves \\ Federal State Budget Institution \\ Leningrad research institute for \\ agricultural science «BELOGORKA» \\ Leningrad region, Gatchina district, \\ v. Belogorka, Russian Federation \\ e-mail: lenniish@mail.ru@mail.ru
}

\author{
Lyudmila P. Smolina \\ Federal State Budget Institution \\ Leningrad research institute for \\ agricultural science «BELOGORKA» \\ Leningrad region, Gatchina district, \\ v. Belogorka, Russian Federation \\ e-mail: lenniish@mail.ru@mail.ru
}

\begin{abstract}
One of the tasks of land use optimization is to exclude low-quality, unprofitable for agriculture land from active agricultural use. Preliminary it is advisable to carry out an indicative assessment of the volume of possible cultural and reclamation activities. Obviously, if the area of unused plots does not exceed $10 \%$ of the area of the crop rotation field, then we can limit ourselves to the localization of these sites, without resorting to special soil-improving measures. In the case when the area under cultivation reaches $30 \%$ of the treated area, it is necessary to conduct a special survey of these lands with the subsequent development of the soil improvement program. With the size of unused plots of more than $30 \%$ of arable land area, it is necessary to develop land reclamation projects and to determine the sources of capital investments for these purposes, or to make a decision to transfer this arable land to other lands, possibly not of agricultural use. At the same time, it is possible to reorient such sites to more economically, environmentally and socially efficient areas. The creation of new agricultural enterprises is associated with the need to attract large investment resources, which the industry currently does not have. At the same time, negative processes can be mitigated by optimizing land use. The structure of acreage is one of the most flexible elements of the system of agriculture and is closely connected with the system of crop rotation. To assess the suitability of soils in the formation of crop rotations, it is necessary to use their agroecological classification.
\end{abstract}

Keywords - optimization; land use structure; heterogeneity; agrolandscapes; cultural activities.

\section{INTRODUCTION}

At the present time, the territory in the region is used traditionally in many respects $[1-7,15]$. But with traditional land use, it is impossible to solve the transition to adaptive intensification of agricultural production when, for example, there are lands in circulation, where genetic traits and agrochemical condition should not be used in intensive farming [14, 18-20]. The economy does not receive the corresponding revenues when investing in them.

The structure of seeding and crop rotation are determined by a significant number of economic factors and soil-climatic nature.

In the aggregate, this group of factors should give an answer to the question to what extent, at what cost, what kind of crop products the enterprise should produce. It is predicated upon the specialization of agriculture, availability of basic production assets, human resources and financial condition. Among the second group of factors, the most important are the permissible saturation limits of crop rotations with certain crops and the degree of suitability of soils to grow these crops, subject to the applicable technologies $[9,10,16]$

\section{MATERIALS AND METHOD}

To evaluate the applicability grade of soils by formation of crop rotations, it is necessary to use their agroecological classification

As it is known, the first category lands are the most valuable in economic sense. In our opinion, it is necessary to use three basic parameters: granulometric composition, humus state, acidity level for diagnostics of these lands on the quantitative basis. Specifically these indices, as a result of their significance for the cultivation of agricultural crops and expensive correction, determine the structure of sowings and 
the nature of land tenure as a whole to a considerable extent. On the same lines, these indices determine the state of a whole series of other characteristics of a soil medium. For example, in the soils similar to the granulometric composition, the content of organic matter determines the agrophysical parameters of the soil medium to a considerable extent. In particular, according to the observations in field experiments, a close link was found between the increase in humus content in soil and growth of the water stability coefficient of soil aggregates. In a similar vein, the amount of agronomical valuable aggregates increases, and the bulk weight of the plow layer is reduced. The steady changes in the agrophysical indices are caused precisely by the level of humus content in the soil [10].

Technogenic factors, such as the method of soil treatment, the type of crop rotation, determine short term seasonal changes in the agrophysical indices.

For quantitative diagnostics of lands concerning their agroecological types, it is necessary to use data on the correspondence of estimation of the actually observed indices of the agrolandscape state to their optimum values. Since these values are ambiguous for certain crops, it is expedient to conduct the estimation regarding the crop with the leading proportion in the crop rotation or regarding the crop with the greatest degree of the product marketability $[10,17,20]$.

On the basis of numerous experimental data for the slightly undulating agrolandscapes with the automorphic soils within the bounds of both Luga-Oredezh River plateau and Silurian plateau, a soil with the content of physical clay within the limits of $10-26 \%$, humus not less than $2.5 \%$ and $\mathrm{pH}>4,6$ with the active soil acidity index can be attributed to the first category. The values of other landscape parameters measured quantitatively and soil indicators should not significantly reduce the value of yields achievable under standard technologies. Otherwise the lands have to be referred to the 2nd category.

According to the existing agroecological classification of lands, one should refer the lands, which have the specific limitations for the effective use of the agrotechnology potential, to the second category $[11,12]$.

The range of these limitations is remarkably wide: these can be insufficiently high indices of the organic matter content in the soils, elements of mineral nourishment, excessive acidity, presence of the small brush-covered sections in the workable outline, etc.

At the same time, no clear quantitative parameters for the evaluation of the harmfulness of these negative factors have been developed yet, which do not allow you to assess the likely effect of applied agricultural technologies objectively, to make accurate calculations of volumes soil-improving measures and the appropriateness of their use. In our opinion, the precise quantitative assessment of negative factors for classification purposes has no practical importance because of their variety and differences in the technical and economic possibilities, by which agricultural producers can eliminate them.
In this case, the classification approach, based on the cost indices, is more expedient. Apparently, in terms of economic feasibility, the cost of neutralizing negative factors has to be covered at the expense of yielding capacity growth or of expenditure reductions connected with the technological process. The payback period must be short - no more than 1-2 years, i.e. the period of both formation and commercialization of yield. The volume of works concerning soil improvement or elimination of other negative factors can be determined on the basis of the existing standards and specifications and of the expenditure calculations to perform necessary works.

The payback period expenditures are determined on the basis of the relationship of expenditures for conducting the cultivating measures and additional income from an increase in productivity. For example, as a result of the low content of the accessible forms of phosphorus and potassium in the soil, the enhanced rates of fertilizers are necessary to obtain the required level of yielding capacity, which will lead to the rise in price of operating expenditures. For cultivation of crops with the high degree of the obtained product marketability, such calculations do not cause difficulties. Certain complexities appear when the soil-improving measures are conducted in the fields, where the crops with no straight commercial outlet, for example, feeding crops, are cultivated. In this case, it is necessary to determine to what extent the carried out operations will increase the effectiveness of the commercial branches, or to make calculations for the conditional estimation of the additional outlet of the feeding crop units.

In practice, a commercial farm may have a significant number of lands which have to be improved, but the resources are usually very limited, and, despite the relatively low costs per unit, the farm has no possibility to carry out soilimproving measures. In this case, it is necessary to use adaptive mechanisms to the maximum. For example, due to the selection of crops resistant to the acidity, it is possible to obtain the relatively high yields of agricultural products without carrying out the liming of acid soils. Special studies in this regard were carried out on the experimental field of Leningrad Agricultural Research Institute "Belogorka".

The research farm relates to the 4 th agroclimatic area of Leningrad region. The climate is characterized by moderate warm summer and by prolonged but unsteady winter with the frequent thaws.

In terms of precipitation volume, the farm relates to a sufficient moistening zone.

The temperature over $10^{\circ} \mathrm{C}$ composes $1500-1700$ in the area, the duration of the frost-free period is 115-120 days. The experimental field is located in the drained part of the Oredezh plateau on the Devonian sandstones. The soil-forming materials are predominantly morainic deposits. Moraine is noncalcareous. Moraine loams to a depth of $50 \mathrm{~cm}$ are strongly washed up by glacial waters; that is why their mechanical composition in the upper part is light and the soils on the morainal mounds have binomial profile. The farm location creates conditions for supremacy of the sod-podzolic soils of different gleization degree, which relates to the types of both sod-podzolic and marshy-podsol soils in the soil cover. 
Mild surface gleization is the area-based feature. The soil formation in this region is characterized by the fact that it occurs on the recently formed quaternary relief, which was formed under the effect of several glacial processes happened at the same time, which resulted in the fairly complicated lithologic landscape. In addition to the presence of large deposits of sand moraines, loamy moraines, binomial deposits represented by sand moraines, underlain by loamy moraines, and three-membered deposits of sand moraines on loamy moraines underlain by Devonian sands, the soil formation is also significantly affected by the difference in the depth of the underlying loamy moraines. The pronounced microrelief also has a strong influence. The large part of the farm lands has been meliorated by means of the open and closed drainage. The land-improvement network was established in the 70's of the past century, and at the present day it needs to be reconstructed. Basic characteristics of the agrolandscape of the experimental field, such as relief, the lithology of soils, their hydrological characteristics, granulometric composition, are favorable or satisfactory in terms of area-based crop farming (table 1).

TABLE I. KKEY FiguRES OF AgROLANDSCAPE CONDITION

\begin{tabular}{|c|c|c|c|}
\hline $\begin{array}{c}\text { Target of } \\
\text { evaluation }\end{array}$ & Criteria & $\begin{array}{l}\text { Optimum } \\
\text { ranges }\end{array}$ & $\begin{array}{c}\text { Actual data of } \\
\text { the research } \\
\text { object }\end{array}$ \\
\hline \multirow{5}{*}{$\begin{array}{l}\text { Relief, } \\
\text { hydrological } \\
\text { conditions }\end{array}$} & a) inclines & $<3$ & below $2^{\circ}$ \\
\hline & \multirow{2}{*}{ b) stoniness } & mild & $70 \%$ of the area \\
\hline & & none & $30 \%$ of the area \\
\hline & \multirow{2}{*}{ c) hydrology } & $\begin{array}{c}\text { no signs of } \\
\text { overwatering }\end{array}$ & $40 \%$ of the area \\
\hline & & hydromorphic & $60 \%$ of the area \\
\hline \multirow{5}{*}{$\begin{array}{l}\text { Adjustable } \\
\text { figures }\end{array}$} & a) humus & $3-4 \%$ & $1.7-3 \%$ \\
\hline & $\begin{array}{l}\text { b) } \mathrm{pH} \text { of } \\
\text { hydrochloric } \\
\text { acid }\end{array}$ & $4,8-5,5$ & $4,5-6,0$ \\
\hline & c) $\mathrm{P} 2 \mathrm{O} 5$ & $\begin{array}{c}20-24 \mathrm{mg} / 100 \mathrm{~g} \\
\text { of the soil }\end{array}$ & $\begin{array}{c}7-30 \mathrm{mg} / 100 \mathrm{~g} \text { of } \\
\text { the soil }\end{array}$ \\
\hline & d) $\mathrm{K} 2 \mathrm{O}$ & $\begin{array}{c}22-28 \mathrm{mg} / 100 \\
\mathrm{~g} \text { of the soil }\end{array}$ & $\begin{array}{c}5-25 \mathrm{mg} / 100 \mathrm{~g} \text { of } \\
\text { the soil }\end{array}$ \\
\hline & $\begin{array}{l}\text { e) thickness of } \\
\text { the ploughed } \\
\text { horizon }\end{array}$ & $24-28 \mathrm{~cm}$ & $22-26 \mathrm{~cm}$ \\
\hline \multirow{3}{*}{$\begin{array}{l}\text { Boundedly } \\
\text { adjustable } \\
\text { figures }\end{array}$} & \multirow{2}{*}{ a) microrelief } & $\begin{array}{l}\text { feebly } \\
\text { marked }\end{array}$ & $\begin{array}{c}\text { feebly marked } \\
60 \% \\
\end{array}$ \\
\hline & & & well-marked $40 \%$ \\
\hline & $\begin{array}{l}\text { b) structural } \\
\text { state of the soil }\end{array}$ & $\begin{array}{c}\text { grainy, } \\
\text { nuciform, } \\
\text { lumpy - the } \\
\text { water-stable } \\
\text { structures }\end{array}$ & $\begin{array}{l}\text { nonpersistently } \\
\text { lumpy, water } \\
\text { permeability } \\
\text { coeff. } 80-90 \%\end{array}$ \\
\hline \multirow{2}{*}{$\begin{array}{c}\text { Conservative } \\
\text { figures }\end{array}$} & $\begin{array}{l}\text { a) parent } \\
\text { materials }\end{array}$ & & $\begin{array}{c}\text { morainal loamy } \\
\text { deposits, binomial } \\
\text { deposits }\end{array}$ \\
\hline & $\begin{array}{l}\text { b)granulometric } \\
\text { composition of } \\
\text { the soil }\end{array}$ & $\begin{array}{c}15-30 \% \text { of } \\
\text { the physical } \\
\text { clay }\end{array}$ & $\begin{array}{l}18-22 \% \text { of the } \\
\text { physical clay }\end{array}$ \\
\hline
\end{tabular}

The cultivable land is almost completely located on the flat surfaces, on slopes which are slightly hazardous in erosional terms (table 2).

TABLE II. DIVISION OF THE FARM LAND BY FORMS AND ELEMENTS OF RELIEF

\begin{tabular}{|c|c|c|}
\hline Relief form (element) & Surface area, ha & Share, $\%$ \\
\hline Water-dividing surfaces & 873.9 & 85.98 \\
\hline Slopes 1-2 & 15.7 & 1.53 \\
\hline Slopes 3-5 & 0.4 & 0.04 \\
\hline Slopes 5-7 & 0.0 & 0.0 \\
\hline Slopes over 7 & 0.2 & 0.02 \\
\hline Hollows & 1.3 & 0.13 \\
\hline Hollow-like lows & 84.0 & 8.2 \\
\hline Foodland's & 40.8 & 4.01 \\
\hline Total: & 1016.3 & 100.0 \\
\hline
\end{tabular}

\section{RESULTS AND DISCUSSION}

As a result of the carried out works, a map of the agroecological land types was created (175 outlines). The land type, which also called as an elementary area of agrolandscape (EAA), is the section uniform in agricultural terms, i.e., limited by the structure of the soil cover, located on the relief element. Each land type was evaluated in the context of the possibility to cultivate a number of crops on it.

TABLE III. LAND USE STRUCTURE OF THE EXPERIMENTAL FIELD

\begin{tabular}{|c|c|c|}
\hline & Square, ha & $\begin{array}{c}\text { \% of square of } \\
\text { agriculturally used } \\
\text { areas }\end{array}$ \\
\hline Total square & 1304 & 100 \\
\hline $\begin{array}{c}\text { Agriculturally } \\
\text { used areas: }\end{array}$ & 993 & 75.8 \\
\hline cultivable land & 752 & 6.5 \\
\hline hayfields & 65 & 17.7 \\
\hline pastures & 176 & $\begin{array}{c}\text { \% of square of } \\
\text { agriculturally used areas }\end{array}$ \\
\hline Total square & 1304 & 100 \\
\hline $\begin{array}{c}\text { Agriculturally } \\
\text { used areas: }\end{array}$ & 993 & 75.8 \\
\hline cultivable land & 752 & \\
\hline
\end{tabular}

When developing the structures and arranging the crop rotations, we were guided by the principle of the adaptation of the crop composition and by the basic parameters of agrolandscape. The large part of the farm lands refers to the II1 category - these are lands suitable for the cultivation of all agricultural crops with the limitations, which we can overcome by means of the simple agrotechnical and cropengineering measures. These are the plain landscapes resistant to erosion and deflation. Among the limiting factors there are 
adjustable factors (acidity, stoniness, brushwood, etc.) (table 4.).

TABLE IV. CROPLAND BRUSHWOOD RATE

\begin{tabular}{|l|c|c|c|}
\hline Crop rotation & $\begin{array}{c}\text { Square, } \\
\text { ha }\end{array}$ & $\begin{array}{c}\text { Brushwood } \\
\text { square, ha }\end{array}$ & $\begin{array}{l}\text { Brush wood } \\
\text { \% }\end{array}$ \\
\hline rotation №1 & 199.6 & 56.0 & 28.0 \\
\hline rotation №2 & 174.0 & 112.0 & 64.4 \\
\hline rotation №3 & 242.1 & 97.0 & 40.0 \\
\hline & 615.7 & 265.0 & 43.0 \\
\hline Total arable lands & 752.0 & 265.0 & 35.2 \\
\hline
\end{tabular}

The brushwood sections of fields are characterized by:

- Soddy low-podzolized soil-gleyed cultivated mild loamy and supersandy soils on sandy moraine underlied by loamy moraine;

- Soddy low-podzolized contact-gleyed mild- and medium-loamy on sandy moraine underlied by loamy moraine.

These soils are formed on watersheds within microholes. Depth of underlay - 55-70 cm. These soil types are characterized by medium gleying degree (blue-gray shade of the horizon, blue patches) of horizon B, from a depth of 40 $\mathrm{cm}$.

Soil profile № 22 - soddy low-podzolized soil-gleyed cultivated moderately arable and mild loamy on sandy moraine underlain by loamy moraine.

The soil has been formed on the watershed in the low locked.

Ang1 - dark gray, newly built, sandy loam, nonpersistently platy, condensed, with ortsteins, includes stones.

Bg 1 - yellow-brown, moist, sabulous, platy, condensed, with ortsteins.

Bg 2 - yellow-brown with the bluish tone, moist, sabulous, platy, condensed, ferrous concretions, stones.

$\operatorname{Dg} 2>55$ - brick, moist, sandy (with the large inclusion of stones), unstructured, dense, includes the layer of gravel, seldom - concretions, spots of ferruginization.

These soils form independent ESA (elementary soil areals), thus, they are background soils in the complex with the soddy low-podzolized mild-gleyed soils, with the soddy low-podzolized soil-gleyed soils of different cultivation degree.

Soil profile № 14 - soddy low-podzolized contact-gleyed, cultivated, moderately arable and mild loamy on sandy moraine underlain by loamy moraine.

The soil has been formed on the mild slope with steepness below $1^{\mathrm{o}}$.

Ang1 - gray, newly formed, mild loamy, sandy, cloddylumpy, condensed, with ortsteins, includes stones. Passage to $\mathrm{A} 2 \mathrm{~B}$ is well-defined.
A2Bg1 yellow-brown with the whitish spots, newly formed, sabulous, platy, condensed, with ortsteins, includes stones.

Bg 1 yellow-brown, moist, sabulous, platy, condensed, includes stones and ortsteins.

CDg2 - yellow-brown, albic with brick spots, moist, medium-loamy, platy-prismatic, condensed, includes stones.

D $>59$ - brick, moist, medium-loamy, prismatic, condensed, includes stones.

These soils form ESA (elementary soil areal), which are distinguished by the cultivation degree and consist of Soddy low-podzolized contact-gleyed soils with the different cultivation degree.

The results of the studies of agriculturally used areas of the experimental field show that in the presence of the relatively small sizes of cultivable land, there are plowed land sections overgrown with bushes and scrubs practically in each crop rotation. The genesis of this phenomenon is most frequently caused by the presence of the spots of gleyed soils in the limits of massif in the complex with the normally moistened or mild gleyey soils. In such sections, there is usually seasonal or moistening of the soil, which makes it difficult to use them as cultivable land. Thus, in the frames of crop rotation fields, there are formed unique 0.01-0.5 ha "spacings" occupied with forest vegetation. In certain cases these formations are the consequence of the poor quality conduction of both land clearance operations and melioration. At the same time, it is unreasonable to bring these sections under cultivation by means of reduction of both shrubs and low forest cover, since most of the "spacings" are connected with the spottiness of the soil cover, and the issue can be resolved only within the framework of improvement of the melioration system of the whole crop rotating section. The nature of forest vegetation also indicates the presence of excessive moisture in these sections. Basic types of vegetation are salix, aspen, alder-tree. The presence of patch effect frequently is not reflected during the soil mapping because of the insignificant sizes of outlines, and for the land-user it becomes necessary to solve these problems as far as they aggravate. Obviously, it is expedient to use sections with the motley soil cover as the long-term stern land. The processes of restoration of natural biocoenoses on hardly suitable cultivable land may have a larger scale. For example, a 18 ha section of gleyed soils was used to grow grass for fodder purposes. In the early 80 's, in consequence of the liquidation of a cattle-breeding farm, there was no need in fodders, and cultural plants in this section were not cultivated. As a result, bushes and scrubs vegetate on it at the present time. Small-contoured sections are also the first to leave the agricultural circulation even with the relatively favorable soil cover.

Thus, with the relatively good fundamental characteristics of the agrolandscape, approximately $35 \%$ of the area of plowed land has almost left the agricultural circulation. Obviously, the land-user will have either to carry out landimprovement of problematic areas or to optimize land use by reducing the area of arable land. 
It is advisable to conduct a rough estimate of possible volumes of the crop-engineering and meliorative measures preliminarily. Obviously, if the sections of unused plots do not exceed $10 \%$ of the crop rotation field square, you can confine yourself with containment of these areas without taking any special soil-improving measures. In the event when non-arable areas reach $30 \%$ of the cultivated section, one should conduct a special survey of these lands followed by the development of a soil improvement program. When the size of the "spacings" is over $30 \%$ of the plowed land area, it is necessary to work out the projects of their improvement and to determine the sources of capital investments for these purposes, or to make a decision about the transfer of this plowed land into the other land, probably into the land which is not intended for agricultural use.

Apparently, natural factors are not the basic reason for the degradation of agricultural land-use. This phenomenon is mainly due to socio-economic factors. At the same time, an analysis of the features of the soil cover will make it possible to use lands more rationally, to develop measures for their improvement and more effective use.

One of the challenges of optimizing land use is the exclusion of low-quality land plots, which are commercially unfeasible for agricultural use from active agricultural use. At the same time, it is possible to reorient them to a more efficient use in other directions in economic, environmental and social terms.

To date, tens of millions of hectares of land used previously for the production of agricultural products have been vacated: cultivable lands, hayfields, pastures. The wasted lands are overgrown with weeds, shrubs, low-value wood species and become unsuitable for use in agriculture without investing large amounts of money. The creation of tree plantations, oriented to the cultivation of economically valuable species in demand by the market, is the most expedient way of using such lands.

Among the main measures in the work on forest development of unused agricultural lands, there is the selection of tree species, which make it possible to create sustainable plantations in the shortest possible time. Creation of plantations of tree species on postagrogenic lands in the taiga zone is advisable to focus on growing coniferous and deciduous species able to produce large woody biomass in a short time. The question of the possible productivity of future plantations naturally arises, which is closely related to soil conditions and their hydrological regime [8]. In accordance with the category of lands and growing conditions, the main species and type of woods (pure or mixed) are determined.

\section{CONCLUSIONS}

For the development of measures for designing optimal agrolandscapes, the following minimum scope of work must be performed:

- to carry out the analysis and conduct an additional survey of land use using planning and cartographic materials, to clarify the areas of land;
- to allocate elementary areas, within which we have to establish the actual state of land and the prospect of a possible transformation in the topographical plan of using the territory;

- to organize a grouping of agrolandscape massifs according to soil parameters, shape, steepness of slopes, exposition and other indicators; that is, it is necessary to distinguish agroecological groups of lands, each of which is characterized by its use and cultivation with economically justified and ecologically permissible intensity in the appropriate crop rotations;

- to identify the lands requiring melioration, as well as the degree and types of necessary land melioration and land clearance operations.

As a result, scarce resources that were inefficiently spent and could be spent on low-quality land can be moved to better lands for technological normalization of crop cultivation and thereby increasing production efficiency. This part of the work also includes improving the technological characteristics of the cultivated sections by eliminating curvedness boundaries, improving the configuration

The next optimization challenge is to increase the efficiency of agriculture on an optimized area of cultivated land in less expensive ways under the modern conditions

\section{References}

[1] A. Erling, "The farming system component of European agricultural landscapes", European Journal of Agronomy, vol. 82, Part B, 2017 pp. 282-291. doi.org/10.1016/j.eja.2016.09.011

[2] Agroecological assessment of lands, design of adaptive-landscape systems of agriculture and agrotechnologies. Methodological guidance, V. I. Kiryushin and A. L. Ivanov Ed. of Akad. Moscow: Russian Academy of Agricultural Science, 2005, p. 783 (In Russian).

[3] B. Bartol, "The significance of quality landscape for life quality. In: Landscape and socie', Council of EuropePublishing, Strasbourg, France, 2006, pp. 74-78. [ $4^{\text {th }}$ meeting of the Workshops for the implementation of the European Landscape Convention, 2006]

[4] M. Benoît, D. Rizzo, E. Marraccini et al, "Landscape agronomy: anew field for addressing agricultural landscape dynamics", LandscEcol, vol. 27, 2012, pp.1385-1394.

[5] R.J.F. Burton, C. Kuczera, G. Schwarz, "Exploring farmers' cultural resistance to voluntary agri-environmental schemes", Sociol Rural, vol. 48, 2008, pp.16-37. doi: 10.1111/j.1467-9523.2008.00452.x

[6] European agricultural landscapes, common agricultural policy and ecosystem services: A review, retrieved from: https://www.researchgate.net/publication/258119439 European agr icultural_landscapes_common_agricultural_policy_and_ecosystem services A review

[7] D’Amico M., Coppola A., Chinnici G. ,Vita G., Pappalardo G, "Agricultural systems in the European Union: an analysis of regional differences", New Medit, no.4, 2013, pp. 28-34.

[8] D.A. Danilov, A.V. Zhigunov, A.N. Krasnovidov, B.N. Ryabinin, V.Yu. Neverovsky, T.A. Shestakova et al, Growing of tree stands on post-agrogenic lands. Saint Petersburg: Publishing house of Polytechnic University, 2016, p.130 (In Russian).

[9] D. A. Ivanov, V. A. Tyulin, L. I. Salikhov, "Productivity of crops in different micro-landscapes”, Agriculture, no. 2, 2000, pp. 18-19. (In Russian) 
[10] A. L. Ilves, O. A. Dragunov, L. P. Smolina, Methods of crop rotation optimization based on efficient use of resources. Kursk, 2004, p. 35 (In Russian).

[11] M. Kleyer, R. Biedermann., K. Henle et al, "Mosaic cycles in agricultural landscapes of Northwest Europe", Basic and Applied Ecology, vol. 8, 2007, pp.295-309

[12] Kiryushin, V. I.(2010) The theory of adaptive landscape agriculture and landscape design. - Moscow, Kolos.- 740 p. (In Russian).

[13] J. Makhzoumi and G. Pungetti, "Ecological landscape design and planning". London: E\&FN Spon, Routledge, p. 1999, 330

[14] Martin et al., "Farming system design to feed the changing world", A review Agron. Sustain. Dev., vol. 33 (131), 2013, pp. 131-149, 10.1007/s13593-011-0075-4

[15] A. Novikova, B. Vaznonis, "Consumers' willingness to pay for agricultural landscape improvements in lithuania: estimation framework research for rural development", vol. 2, 2017, pp. 249255. DOI:10.22616/rrd.23.2017.075

[16] M.L. Paracchini, T.P. Correia, I. Loupa-Ramos, C. Capitani, L. Madeira, "Progress in indicators to assess agricultural landscape valuation: How and what is measured at different levels of overnance", Land use Policy, vol. 53, 2016, pp. 71 - 85. DOI: 10.1016/j.landusepol.2015.05.025

[17] V. A. Semenov, Evaluation of land and forecast of the crop. Moscow:Lenizdat, 1977, p. 94 (In Russian).

[18] C. J. Vasseur, S. Aviron, F. Burel, J.-M. Meynard, J. Baudry, "The cropping systems mosaic: how does the hidden heterogeneity of agricultural landscapes drive arthropod populations", Agricult. Ecosyst. Environ., vol. 166, 2013, pp. 3-14, 10.1016/j.agee.2012.08.013

[19] B. Zanten, P. H. Verburg, M. Espinosa et al, "European agricultural landscapes, common agricultural policyand ecosystem services: a review", Agronomy for Sustainable Development, vol. 34, no. 2, 2014, pp 309-325

[20] E.H. Zanden, Agricultural landscapes in Europe: spatial structure, land management and consequences of agricultural abandonment, $\mathrm{PhD}$ thesis, 2016, p. 204

[21] J. Wery and J.W.A. Langeveld, "Introduction to the EJA special issue on cropping systems design: new methods for new challenges", Eur. J. Agron., vol. 32 (1), 2010, pp. 1-2, 10.1016/j.eja.2009.10.001 